\title{
Ceramic / Inorganic-Organic Nano-Hybrid Composites for Thermally Stable Insulation of Electrical Wires: Part II- Properties of the Composite Insulated Wires
}

\author{
Yong-Xin Pang and Simon N.B. Hodgson \\ School of Science, Engineering and Design \\ Teesside University \\ Middlesbrough TS1 3BX, United Kingdom
}

\begin{abstract}
The paper Part I reported on the fabrication of high temperature capable electrical wires insulated with a new type of composite coatings comprising particulate ceramics and silicon-containing inorganic-organic nano-hybrids. This second paper studies the thermal, mechanical and dielectric properties of these composite insulated wires in accordance with relevant national standards. Techniques for materials characterization were also applied to provide information for better understanding the coatings' performance as wire insulation. Results showed that insulated wires have moderate dielectric strength comparable to ceramic insulation and excellent thermal stability, with insulation sustained for over 100 days at $500^{\circ} \mathrm{C}$ and prolonged period at $450^{\circ} \mathrm{C}$ under constant high temperature ageing and there is no obvious insulation degradation after thermal cycling for 20 times. The insulated wires demonstrated good mechanical properties, with interim flexibility allowing a minimal bending radius of $3 \mathrm{~mm}$ for 1.2 mm insulated wires. The resistance to abrasion and cutting through are also good enough to satisfy most practical applications.
\end{abstract}

Index Terms - ceramic composite insulated wires, insulation structure, high temperature ageing, breakdown voltage, thermal performance, mechanical properties

\section{INTRODUCTION}

THE development of electrical machines for operating in high temperature environments places significant demands on the thermal stability of the components associated with the machines. An essential and arguably most important component is the stator winding insulation system, which mainly includes strand, turn and groundwall insulations and other parts of coil-core assembly such as slot liners, impregnants/encapsulants and end caps [1]. The thermal stability of the insulation system used inside an electrical machine fundamentally determines its upper-limit temperature of operation, because insulation materials lose their dielectric property at an increasing rate once the temperature is beyond their decomposition temperature [2]. There are constraints to enhance thermal stability of insulation materials, especially for wire insulation, where high dielectric strength and mechanical flexibility are essential. The emerging high temperature applications potentially require the insulation to be functional at temperatures of ca. $500^{\circ} \mathrm{C}$, withstanding high temperature environments, but also the Ohmic generated heat in conductor wires when much higher power input is used for enhanced machine efficiency $[3,4]$. Such a high temperature precludes conventional

Manuscript received on 20 June 2019, in final form 24 September 2019, accepted xx Month 20yy. Corresponding author: Y-X. Pang. insulation with organic materials whose service temperature upperlimit is about $250^{\circ} \mathrm{C}$ even for the most exotic systems due to polymer decomposition, leading to insulation breakdown and short-circuiting. Conversely, inorganic materials (e.g. glass and ceramics) have service temperatures well above the target requirement, and have been applied in electrical insulation [5, 6]. However, their mechanical performance is far from satisfactory for wire insulation because these materials are hard and brittle in nature, which makes it impossible to survive a coil-winding process when used as wire insulation. Alternatively, plate-shaped ceramic particles were formed into thin sheets to impose mechanical bendability for electrical insulation such as mica papers [7, 8]; however, the utilization of organic resin binders limited the enhancement of thermal performance. A commercial mica tape braided wire SK-650 from Von Roll offers temperature resistance beyond $500^{\circ} \mathrm{C}$ [9], but the loose contact of the mica tape to the wire and the thick braid is unfavorable for fabrication of dense windings. Based on the best of our knowledge, there was no existing coating capable of $500^{\circ} \mathrm{C}$, either organic or inorganic, which could deliver the insulation, which simultaneously meets the dielectric, thermal and mechanical performances for electrical wire insulation. The high temperature of electrical wires presents a tough challenge against the existing materials and concepts of electrical wire insulation and is the subject of this investigation. 
This work explores inorganic composites comprising particulate ceramics and silicon-based inorganic-organic nanohybrids for electrical wire insulation to achieve high temperature capability. The nano-hybrids can form high temperature insulating coatings which has been demonstrated in insulating soft magnetic composites capable of annealing at above $500^{\circ} \mathrm{C}$ [10]. The utilisation of nano-hybrids affords the composite coatings with the mechanical flexibility needed in winding process and may be later converted to full inorganic insulation bearing high temperature capability. The Part I of this work reports fundamentals and formulations of the composite coatings, this part studies the thermal, mechanical and dielectric performance of the electrical wires insulated with the composite coatings.

\section{EXPERIMENTAL}

\subsection{PREPARATION OF INSULATED WIRES WITH GRADIENT COMPOSITION COATINGS}

The detailed procedures for preparing ceramic/inorganicorganic nano-hybrids composite coatings and the coated wires were described in the Part I of this research. Typically, three different coatings were applied onto the conductor wires to form an integrated insulation with gradient compositions, where the innermost prime coating layer contains least organic content and the outer layer contains the most organic moieties (Fig. 1). The variation of organic contents in the composite coatings is achieved by adjusting relative amounts of various organosilanes selected from methyltrimethoxysilane (MTMS), (3-glycidyloxypropyl)trimethoxysilane (GPTMS) and phenyltriethoxysilane (PhTES) during synthesis of the nanohybrids and Table 1 summarizes typical compositions of each coating. Each of these coatings was consecutively applied on the wire to form the integrated insulation through a reel-to-reel continuous coating process.

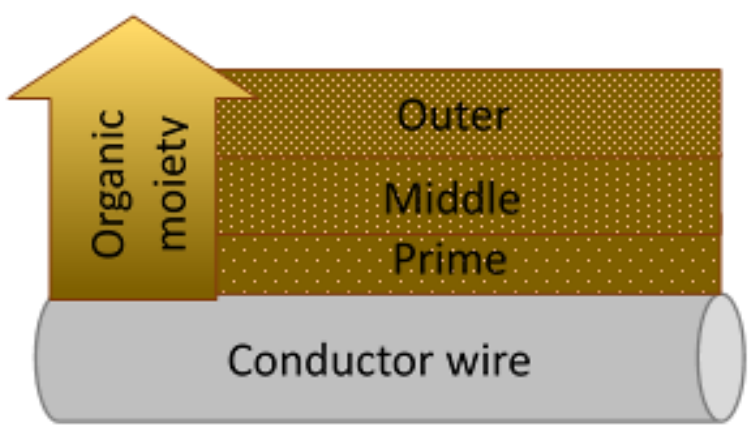

Figure 1. Diagram of integrated insulation coating with gradient composition on a wire (not drawn to scale).

Table 1. Typical composition of the individual layer of coatings.

\begin{tabular}{|c|c|c|c|c|c|}
\hline \multirow[t]{2}{*}{ Coating } & \multirow{2}{*}{$\begin{array}{l}\text { Organic content } \\
\text { (wt. \%) }\end{array}$} & \multicolumn{3}{|c|}{ Organic moiety (mol.\%) } & \multirow{2}{*}{$\begin{array}{l}\text { Layer thickness } \\
\qquad(\mu \mathrm{m})\end{array}$} \\
\hline & & $\mathrm{Me}^{*}$ & GP & $\mathrm{Ph}$ & \\
\hline Outer & 26.1 & 80 & 20 & 0 & $14-18$ \\
\hline Middle & 23.2 & 85 & 12 & 3 & $12-15$ \\
\hline Inner & 19.9 & 94 & 5 & 1 & $5-8$ \\
\hline
\end{tabular}

* Me - methyl; GP - glycidyloxypropyl; $\mathrm{Ph}$ - phenyl

\subsection{PROCEDURE}

\subsubsection{Thermal tests}

First, wires insulated with the ceramic / inorganic-organic nanohybrid composites were made into twisted wire pairs following the British Standard EN 60851-5. Thermal treatment of wire specimens was carried out in two settings - thermal ageing respectively at 450,500 and $550^{\circ} \mathrm{C}$ for prolonged time and thermal cycling by repeatedly heating specimens to $450^{\circ} \mathrm{C}$, keeping at the temperature for 10 hours, and then cooling to room temperature. After thermal treatment, at least five twisted wire pairs were tested and the average breakdown voltage reported for each data point.

\subsubsection{Mechanical tests}

The mechanical properties of the composite insulated wires were tested following British Standard EN 60851-3.

The minimal bending radius of composite insulated wires was measured by winding the wire on a polished mandrel with ten continuous turns and then observing the coating integrity with a magnifier. The smallest mandrel radius is taken as the minimal bending radius of the insulated wire without coating damage observed for the wire turns on the mandrel.

Abrasion resistance of the coated was tested according to the procedure of BS EN60851-3 2009, Test 11: Resistance to Abrasion. In principle, an abrasion head with a $0.5 \mathrm{~mm}$ diameter tip is placed on a piece of straightened wire, which is supported on an anvil. The abrasion head slides on the wire at the speed of $400 \pm 40$ $\mathrm{mm} / \mathrm{min}$ while exerts an increasing force on the wire. Both the wire and abrasion head are connected to an electrical relay circuit. As the insulation coating is abraded, the electric connection forms between abrasion head and wire and trigger the abrasion head stop. Five measurements were performed for each wire sample and the average force reported. The force exerted on the wire at this breaking point is taken as the measure of abrasion resistance, which is then calculated from the traveling distance of abrasion head and the load added.

Dynamic cut-through testing was conducted following ASTM D3032-10. The standard cutting edge consists of a sewing needle of $0.55 \mathrm{~mm}$ diameter attached on the $90^{\circ}$ tapered edge of a brass block. The cut-through was carried out on a universal mechanical tester and the operating procedure was as follows. The cutting edge is placed cross over a straight wire on an anvil. Before applying force on the cutting edge, a $12 \mathrm{~V}$ voltage is applied between the wire and the cutting edge and an ammeter is connected in the circuit. The tester then start to exert the cutting edge against the wire at a travelling speed of $3 \mathrm{~mm} / \mathrm{min}$. The cutting edge immediately stops when electrical contact between the wire and cutting edge is established and the pressing force at that point is recorded as the "cut-through force". For each wire sample, 6 measurements were made and the average and standard deviation reported.

\subsection{CHARACTERIZATION AND MEASUREMENTS}

Breakdown voltage was measured using twisted pairs of insulated wires according to the BS EN 60851-3.

The analysis of attenuated total reflectance Fourier transform infrared spectroscopy (ATR-FTIR) was conducted on a Thermo Nicolet 5700 FTIR spectrometer. All spectra were taken in wavenumber range between 650 and $4000 \mathrm{~cm}^{-1}$ at $4 \mathrm{~cm}^{-1}$ resolution, averaging over 32 scans.

Contact angle measurements were performed on a Krüss Drop Shape Analysis System DSA100, using purity water as the detecting liquid. Coatings were applied on glass slides to allow 
the measurements, instead of the insulated wire. Ageing was carried out at different temperatures for 2 days.

Thermal analyses were conducted using a Thermatrix STA-1500 TGA/DSC simultaneous analyzer from room temperature to $800^{\circ} \mathrm{C}$ at the ramp $10^{\circ} \mathrm{C} / \mathrm{min}$ in static air or under argon flow of $30 \mathrm{~mL} / \mathrm{min}$.

\section{RESULTS AND DISCUSSION}

\subsection{THERMAL PERFORMANCE OF COATED WIRES}

Thermal stability of the insulated wires is the major objective to achieve for this research and thus it is studied in two ways: ageing at specified temperature against time and cyclic heating and cooling. Figure 2 shows the dielectric property of insulated wires as a function of intensive ageing at elevated temperatures. There is a quick drop of breakdown voltage (BV) at initial heating stage, followed by a relatively gradual decease as ageing proceeded. The BV decrease rate depends on ageing temperature, with higher ageing temperature resulting in quicker reduction. BV drops below $500 \mathrm{~V}$, the threshold set as the endpoint according to testing standard, after 1000 hours at $550^{\circ} \mathrm{C}$, and over 2600 hours at $500^{\circ} \mathrm{C}$. However, it is interesting that the $\mathrm{BV}$ retains almost constant for $450^{\circ} \mathrm{C}$ ageing at the time span of this experiment.

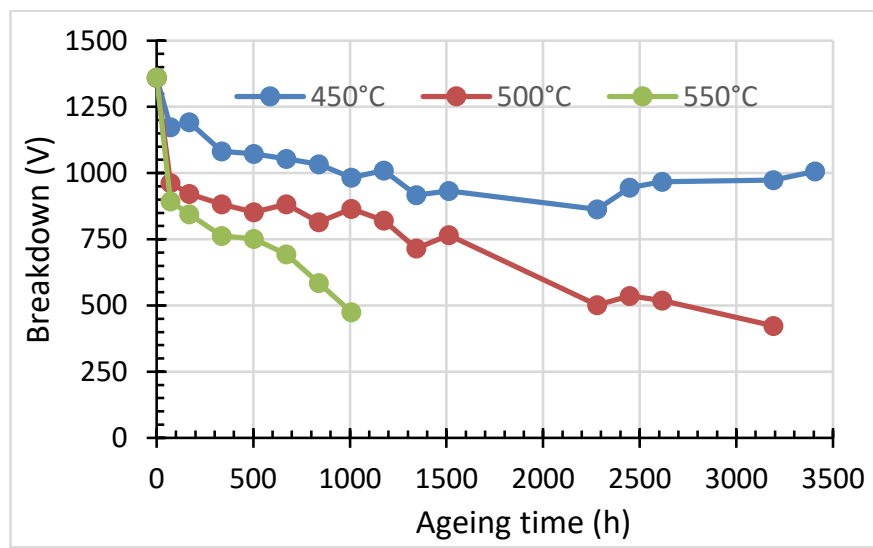

Figure 2. Breakdown voltage of the composite coated wires as a function of intensive ageing at different temperature.

The initial quick BV drop comes from the loss of organic moieties containing inside nano-hybrid of the composite coating (Table 1), especially the glycidyloxypropyl (GP) groups which have lower thermal stability as proved in paper 1 of this research. Figure 3 shows the ATR-FTIR spectra of the insulated wires after ageing for two days at different temperatures. The absorption band at $1270 \mathrm{~cm}^{-1}$ attributes to the $\mathrm{C}-\mathrm{H}$ bond vibration of organic moiety in the composite coating [11] and its intensity reduces with the increase in ageing temperature. The absorption band at $758 \mathrm{~cm}^{-1}$ assigned to the $\mathrm{Si}-\mathrm{O}$ and $\mathrm{Si}$ $\mathrm{CH}_{3}$ stretching shifts towards high wavenumber as ageing temperature increases, accompanied by reduction of peak intensity due to loss of methyl group. This band shifting also reflects the structural change of $\mathrm{Si}-\mathrm{CH}_{3}$ to $\mathrm{Si}-\mathrm{O}$, caused by the oxidative decomposition of methyl group $[11,12]$. The band at $1000 \mathrm{~cm}^{-1}$, also belonging to $\mathrm{Si}-\mathrm{O}$ and $\mathrm{Si}-\mathrm{CH}_{3}$ stretching, becomes broad with increasing ageing temperature. The absorption bands at 1080 and $1198 \mathrm{~cm}^{-1}$, assigning to glycidoxy and propylene groups from GP [13], disappeared after $450^{\circ} \mathrm{C}$ ageing because of its lower thermal stability compared with methyl group. In summary, the change of these characteristic absorption bands reflects the structure evolution of the composite coating during high temperature ageing.

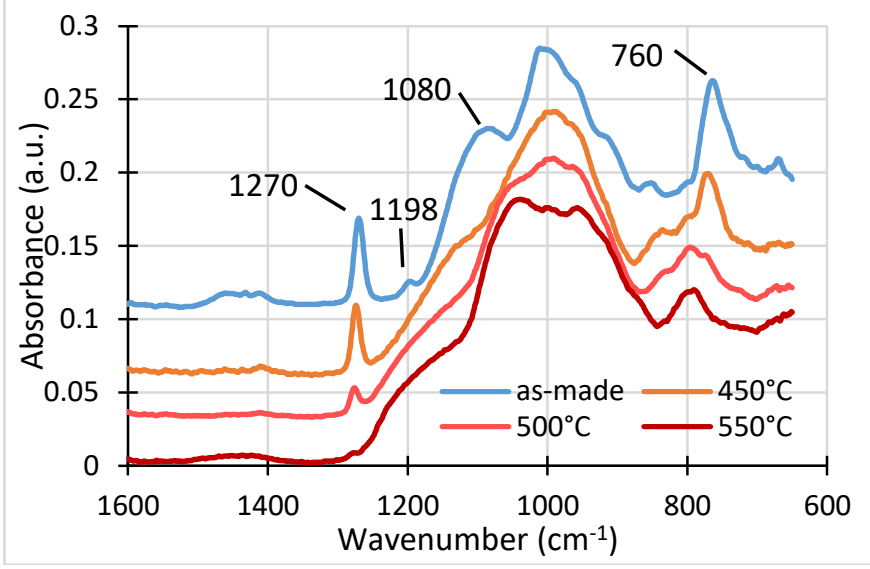

Figure 3. ATR-FTIR spectra of the composite coated wire after heat treatment at various temperatures for 2 days.

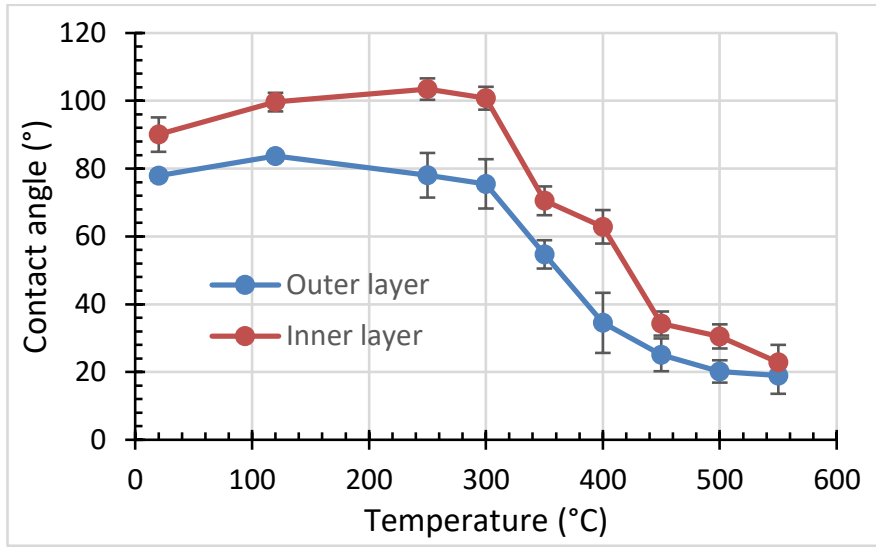

Figure 4. Contact angles of two composite coatings coated on glass slides after heat treatment at various temperatures for 2 days. (cf. Table 1 for coating formulas).

Ageing at high temperature also changes surface energy of the composite coating because of the loss or oxidation of organic moiety of the coating, and this can be revealed by measuring variation of the contact angle (CA) of aged coatings. As shown in Figure 4, the CA of both coating formulas varies with the ageing temperature. The relatively higher $\mathrm{CA}$ from inner layer formulation results from the high methyl content of the coating (Table 1), because methyl group has lower surface energy and hence higher CA compared with GP and phenyl groups [14]. The initial heating at $120^{\circ} \mathrm{C}$ leads to CA increase because it actually acts as a post-curing process, which promotes further polycondenzation of the nano-hybrid component in the composite coatings, which does not cause any oxidation of the organic moiety. When heated at $250^{\circ} \mathrm{C}$, the $\mathrm{CA}$ of inner layer coating rises further, but the outer layer formulation shows a slight decline of the CA, which may be attributed to the start of oxidation of GP group at coating surface. As the ageing temperature increases to $300^{\circ} \mathrm{C}, \mathrm{CA}$ starts to decrease for both coatings accelerating with further rise in ageing temperature. The decrease of $\mathrm{CA}$ is due to partial oxidation of organic moiety occurring in the temperature range 
of 300 to $450^{\circ} \mathrm{C}$ because the GP group is still detectable by ATR-FTIR (Figure 3) and both loss and oxidation of organic moiety contribute to the $\mathrm{CA}$ decline at ageing temperature above $450^{\circ} \mathrm{C}$ where absorption band of GP group disappeared in ATR-FTIR spectra.

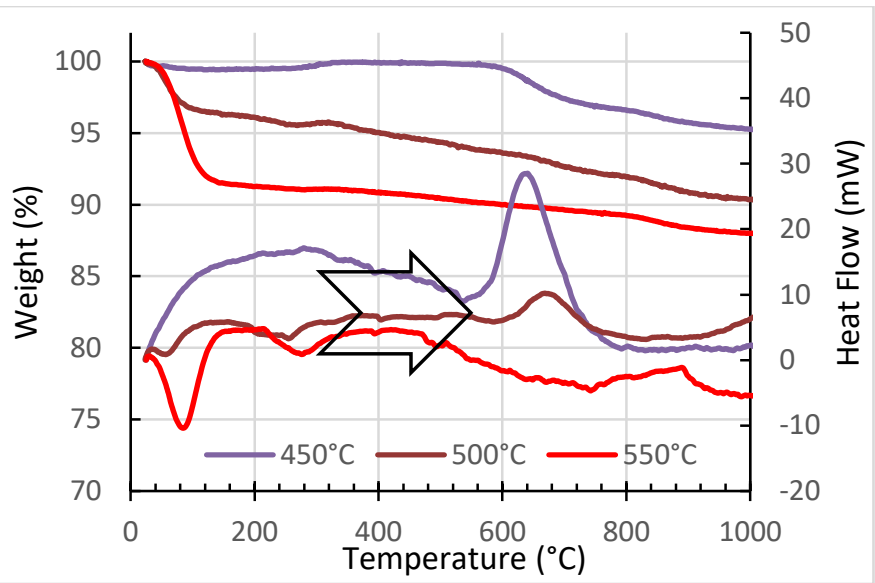

Figure 5. Thermal analysis of the composite insulated wire after ageing at different temperatures for 2 days.

Table 2. DSC determination of decomposition peak temperature and area of the organic moiety aged at various temperatures and time.

\begin{tabular}{lllllll} 
& \multicolumn{3}{c}{ the organic moiety aged at various temperatures and time. } \\
\hline \multirow{2}{*}{$\begin{array}{l}\text { Ageing } \\
\text { time (day) }\end{array}$} & \multicolumn{3}{c}{ Peak temperature $\left({ }^{\circ} \mathrm{C}\right)$} & \multicolumn{4}{c}{ Energy release $(\mathrm{W} / \mathrm{g})$} \\
\cline { 2 - 7 } & $450^{\circ} \mathrm{C}$ & $500{ }^{\circ} \mathrm{C}$ & $550{ }^{\circ} \mathrm{C}$ & $450{ }^{\circ} \mathrm{C}$ & $500^{\circ} \mathrm{C}$ & $550^{\circ} \mathrm{C}$ \\
\hline 1 & 644 & 669 & 696 & 1574 & 781 & 148.5 \\
2 & 641 & 668 & - & 1417 & 437 & - \\
3 & 655 & 673 & - & 861 & 300 & - \\
7 & 665 & 676 & - & 742 & 73 & - \\
28 & 677 & 678 & - & 281 & 53 & - \\
56 & 674 & 673 & - & 80 & 12 & - \\
95 & 677 & - & - & 24 & - & - \\
\hline
\end{tabular}

Thermal analyses were applied to check variation of the composite coating with high temperature ageing. Figure 5 displays thermographs of the coatings scratched off the aged wires, showing significant influence of ageing temperature. For the composite coating aged at $450^{\circ} \mathrm{C}$, the TGA signal shows a slight weight increase around $300^{\circ} \mathrm{C}$ from partial oxidation of organic moiety. A main weight loss occurs above $560^{\circ} \mathrm{C}$, which results from burnout of organic moiety. Correspondingly, there is a shallow exothermic hump around $300^{\circ} \mathrm{C}$ and large exothermic peak from 560 to $680^{\circ} \mathrm{C}$ on DSC signal, respectively reflecting heat release from the oxidation and burning out of organic moiety. For the wire aged at $500^{\circ} \mathrm{C}$, the small weight increase at $300^{\circ} \mathrm{C}$ and weight loss above $560^{\circ} \mathrm{C}$ on TGA signal are still detectable, but the sizes became much smaller due to less amount of organic moiety existing in the composite coating. The DSC curve accordingly shows the smaller exothermic peak of burning out organic moiety, but the peak temperature is higher compared the sample aged at $450^{\circ} \mathrm{C}$. It is noticeable that the $500^{\circ} \mathrm{C}$ aged sample has a substantial weight loss at lower temperature end $\left(<180^{\circ} \mathrm{C}\right)$ which is an endothermic event as revealed on DSC signal. This attributes to the drive out of moisture absorbed inside the composite coating, implying the quick burnout of organic moiety may lead to formation of pores in the composite coating. For the sample aged at $550^{\circ} \mathrm{C}$, the moisture intake is much higher and there is no exothermic peak of burning out organic moiety on DSC curve, suggest all organic phase were removed after 2 day ageing at this temperature.

Table 2 summarized the DSC peak temperature and area of burning out organic phase during ageing process at different time and temperatures. The decomposition peak temperature of organic moiety generally increases with ageing time as well as temperature. This raised peak temperature is due to the remaining residue organic moiety being embedded in the inorganic phase, which retards oxygen diffusing to the organic residue and thus delays the oxidative decomposition. The peak area, representing residue organic moiety after ageing for a period of time, constantly decreases with ageing time and temperature. It shows that there is no organic residue present after 2 days ageing at $550^{\circ} \mathrm{C}$, whereas the component is still detectable after 56 day at $500 \mathrm{C}$ and 95 days at $450^{\circ} \mathrm{C}$. This result is in consistence with the $\mathrm{BV}$ measurement as shown in Figure 2 and suggests the slower the loss of organic moiety, the better the dielectric property of the aged wire.

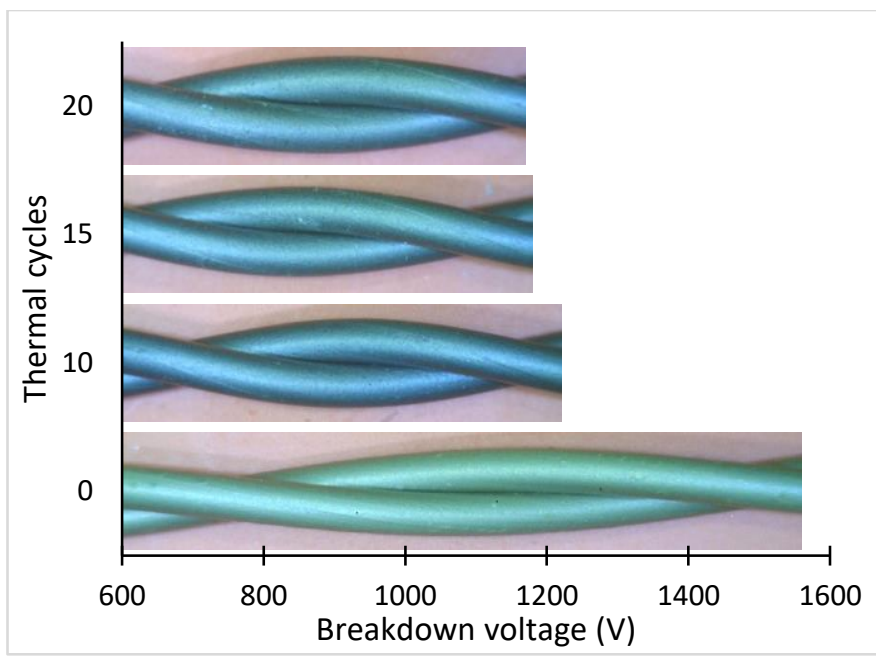

Figure 6. Thermal cycling of the composite insulated wire twists and its influence on breakdown voltage. Cycling condition: heating to $450^{\circ} \mathrm{C}$, soaking for 10 hours and cooling down to room temperature.

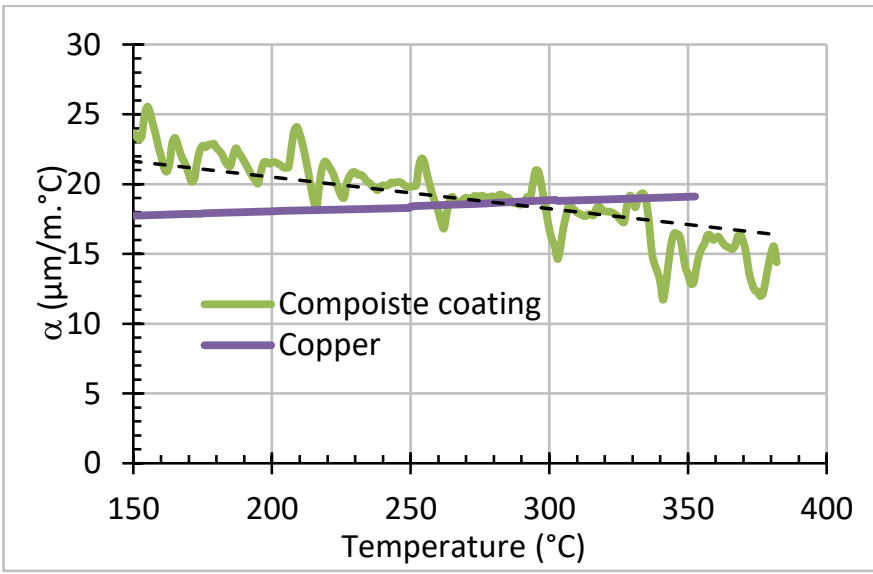

Figure 7. Coefficients of thermal expansion of copper and the composite coating as a function of temperature.

The thermal performance of insulated wires was also evaluated by cyclic heating / cooling tests and the results are presented in Figure 6. It shows that the composite coating 
remains integrity without cracking or de-bonding development after 20 thermal cycles and the breakdown voltage initially decreases quickly over the first few thermal cycles, but it gradually stabilizes as cycle number increases. This good thermal cycling performance implies the composite coatings have similar thermal expansion property to the copper conductor, and the coatings have the ability to tolerate any resultant thermally induced stresses from this heat cycling. As shown in figure 7 , the two materials have similar coefficient of thermal expansion at around $280^{\circ} \mathrm{C}$ and the difference may be within $15 \%$ at $450^{\circ} \mathrm{C}$ as estimated from the trend of the lines.

\subsection{MECHANICAL PROPERTIES OF COATED WIRES}

The mechanical properties of coated wires are important with respect to coil manufacture and installation processes, as well as other physical impacts during handling and operating, such as vibration. Mechanical flexibility is essential for winding the insulated wire into coils. For these composite coatings, the predominant amount (over 70\%) of non-flexible inorganic materials in the composition determines that they are much less mechanically flexible compared with organic enamels. The formulations have been developed to ensure that sufficient flexibility is retained to facilitate manufacturing of most coil geometries. Once the shape has been formed, the organic component can be subsequently removed in situ to form the final high temperature capable electrical insulation without loss of integrity The ability to tolerate a small bending radius is preferred for placing less impact on coil geometry and winding operation. Incorporation of higher organic content in the initial composite may improve flexibility of coatings, but higher organic component has inverse influence on thermal stability of the final composite coatings and its burning out at high temperature impairs integrity of the coatings or even causes cracking if its percentage is too high. For a given organic content of the composite coatings, the formulation is thus optimized between these two competing parameters. The flexibility for optimization of insulated wires is achievable to some extent by control over the fabrication conditions (which was discussed in Part I of this research), the coating structure, and thickness.
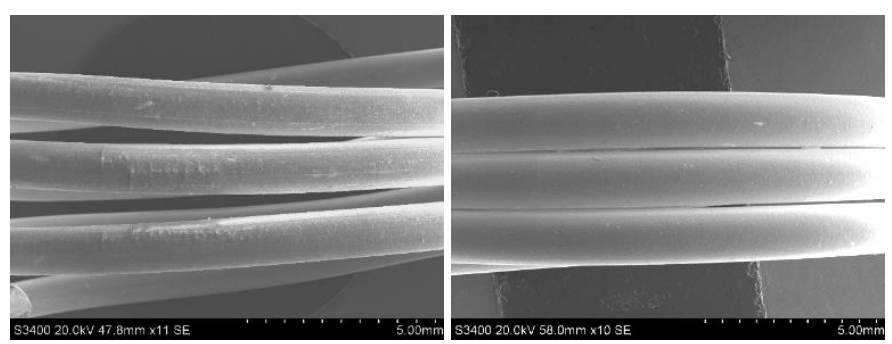

Figure 8. SEM micrographs showing effect of coating structure on bending property of the composite insulated wire (Left: uniform composition comprising $27 \mu \mathrm{m}$ middle coating containing $23.2 \%$ organic moiety; Right: gradient composition comprising $16 \mu \mathrm{m}$ prime coating and $14 \mu \mathrm{m}$ outer coating with the overall organic content of $22.8 \%$, cf. Table 1 ).
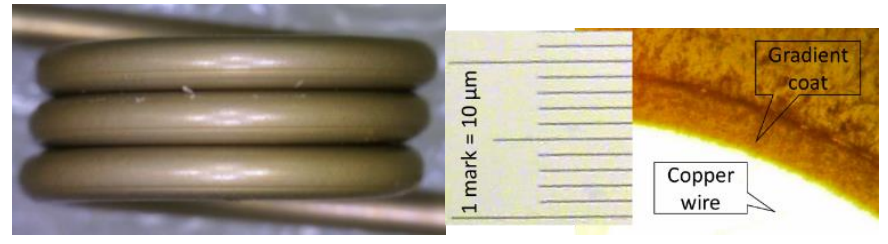

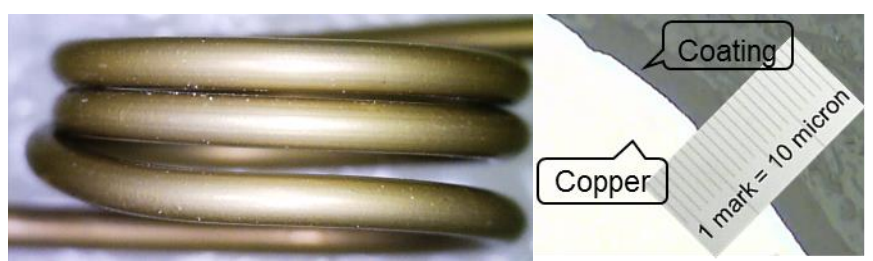

Figure 9. Effect of coating thickness on bending property of the composite insulated wires (top: $30 \mu \mathrm{m}$ insulation bent at $\mathrm{r}=3 \mathrm{~mm}$, and bottom: $40 \mu \mathrm{m}$ insulation bent at $\mathrm{r}=5 \mathrm{~mm}$ ).

Figure 8 compares the bending performance of wires insulated with coatings consisting of similar amount of organic content, but with different structure, visualizing the effect of coating structure on the bending performance. The composite coating with gradient composition, where the inner layer has the lowest content of organic moiety and the outer layer has the highest content, shows better bending property than the counterpart with uniform composition. The good bending property of gradient structure results from such gradient structures better matching the deformation profile of the bending wire where the outer coating is subject to more deformation during bending operation.

The coating thickness is another factor influence the bending property. As depicted in Figure 9, the insulated wire can be bent to a radius of $3 \mathrm{~mm}$ when coating thickness is $30 \mu \mathrm{m}$, and to $5 \mathrm{~mm}$ radius when the coating thickness increases to $40 \mu \mathrm{m}$. Such bending radius can meet winding requirement in most situations. This effect of coating thickness comes from the increased deformation of outer layer as the whole insulation increases.

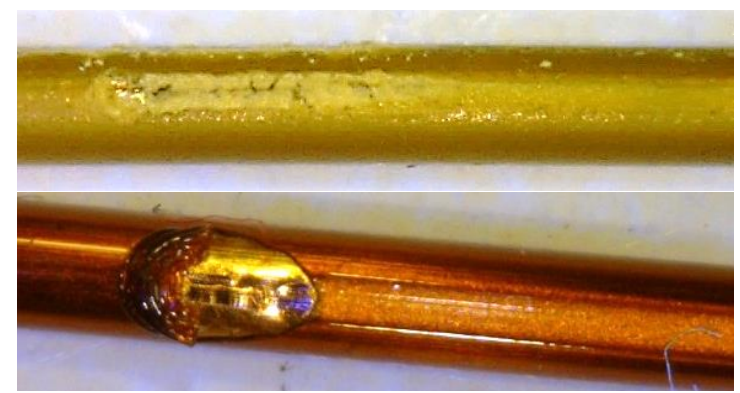

Figure 10. Damage of composite coating insulated wire and commercial polyimide insulated wire after abrasion tests.

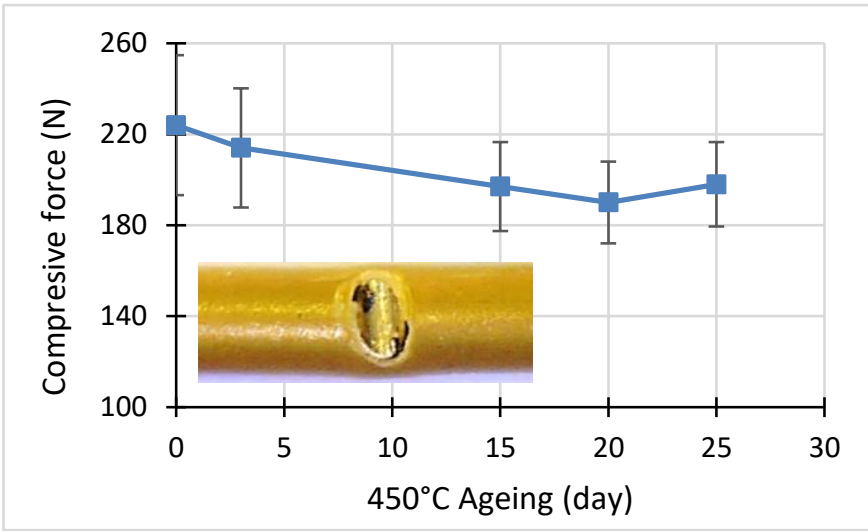

Figure 11. Cutting through force as a function of ageing time at $450^{\circ} \mathrm{C}$ (Inset picture: the cut damage of tested wire).

Abrasion resistance of the composite insulated wire was tested following BS EN60851-3 2009, Test 11. Figure 10 depicts the damaged composite coating and polyimide coating after the test. It shows different abrasion modes for these two types of insulation 
coating. The composite coating was consecutively worn off as the exerting pressure increased, without spallation or peel-off of the composite coating from the conductor, whereas the polyimide coating is suddenly scratched away from the conductor when the applied force rises to a critical value, which indicates there is no wearing but damage of polyimide coating during abrasion test. The force causing the abrasion damage was measured as $1.2 \mathrm{~kg}$ for composite coating and $3.4 \mathrm{~kg}$ for polyimide coating.

Dynamic cut-through testing was conducted following ASTM D3032-10 standard for evaluating stability of the insulation coating against the mechanical pressure from a sharp object. Fig. 11 displays the cut-through force of the composite coating insulated wires as a function of ageing time at $450^{\circ} \mathrm{C}$. In general, the cutthrough resistance gradually degrades with ageing time and then plateaus at similar level after ageing for 15 days. When the applied pressure is higher than the yield strength of the wire conductor, the cutting edge of test tool indents into the wire and causes insulation coating deformation. The composite coating possesses certain mechanical flexibility, which allows it to deform along with the conductor, but it breaks when the deformation is larger than elongation at break of the material. The initial decrease of cutthrough force with increasing ageing time originates from the gradual loss of some organic moiety during high temperature ageing process, due to the coating becomes less flexible; as the ageing continues, the coating's mechanical properties stabilized and thus the cut-through force retains at similar level, without further decrease with ageing time.

\section{CONCLUSIONS}

The comprehensive characterization and tests confirmed the electrical wire insulated with the special ceramic based composites possesses excellent thermal stability, moderate mechanical flexibility and dielectric strength, which make it unique from conventional polymer and ceramic insulated wires. The excellent thermal stability of these composite coating materials imparts the wire with very high temperature endurance up to $500^{\circ} \mathrm{C}$ far beyond the temperatures polymer insulation could achieve, and the interim mechanical flexibility allows winding the wire made into coils with $3 \mathrm{~mm}$ minimal radius, far superior to the deformation ceramic insulation could perform.

The work opens an innovative route for developing high performance electrical insulations and this new type of insulated wire provides an alternative choice for design and fabrication of electrical machines capable of operating at temperature well above current electrical machine would be able to withstand. It has favourable perspective in many potential applications in traditional sectors, such as fire security and emerging technological areas, e.g. electric aircrafts.

\section{ACKNOWLEDGMENT}

The authors gratefully appreciate the financial support of DTI Technology Programme with Project No. TP/2ET/6/I/10032, from the former Department of Trade and Industry, United Kingdom.
[1] G. C. Stone, I. Culbert, E. A. Boulter and H. Dhirani, Electrical Insulation for Rotating Machines: Chapter 1 Rotating Machine Insulation systems, Power Engineering Series, Wiley-IEEE Press, 2014.

[2] G. C. Montanari and F. J. Lebok, "Thermal degradation of electrical insulating materials and the thermokinetic background," IEEE Trans. Electr. Insul., vol. 25 no.6, pp 1029-1036.

[3] J. A. Rosero, J. A.Ortega, E. Aldabas L. Romeral, "Moving towards a more electric aircraft," IEEE A\&E Systems Mag., vol.22, no.3, pp. 3-9, March 2007.

[4] J. Thompson, M. Rossing, "High-temperature downhole motor facilitates cleanout of obstructed thermal well, saving production downtime," SPE/ICoTA Coiled Tubing \& Well Intervention Conference and Exhibition, 2011.

[5] E. Celik, I. H. Mutlu and Y. S. Hascicek, "Electrical properties of $\mathrm{MgO}-$ $\mathrm{ZrO} 2$ insulation coatings on $\mathrm{Ag}$ and $\mathrm{AgMg} / \mathrm{Bi}-2212$ tapes for magnet technology," Scripta Materialia, vol. 47, pp. 315-320, 2002.

[6] T. Oldinga, M. Sayera and D. Barrow, "Ceramic sol-gel composite coatings for electrical insulation," Thin Solid Films, vol. 398-399, pp. 581-586, 2001.

[7] S. Harabayashi, K. Shibayama, S. Matsuda and S. Roll, "Development of new mica paper epoxy insulation systems for high voltage rotating machine," IEEE Electr. Insul. Conf.(EIC), 1973, pp. 90-91.

[8] S. UI Haq and R. Omranipour, "Accelerated life testing of high voltage stator coils with enhanced PET-mica insulation system,"IEEE Electr. Insul. Conf.(EIC), 2011, pp. 90-91.

[9] Von Roll, "technical specification for SK-650", https://www.vonroll.com/en/products/electricalconductors/round-wires/?id=7648ca4e

[10] Y. X. Pang, S. N. B. Hodgson, J. Koniarek and B. Weglinski, "The influence of the dielectric on the properties of dielectromagnetic soft magnetic composites. Investigations with silica and silica nano-hybrid sol-gel derived model dielectric," J. Mag. and Mag. Mater., vol. 310, pp 83-91, 2007.

[11] Z. Olejniczak et al, “29 Si MAS NMR and FTIR study of inorganicorganic hybrid gels," J. Molecular Structure, vol. 744-747, pp. 465-471, 2005.

[12] S. Nemeth and Y. C. Liu, "Mechanical properties of hybrid sol-gel derived films as a function of composition and thermal treatment," Thin Solid Films, vol. 517, pp. 4888, 2009.

[13] I. M. Šapić, L. Bistričić, V. Volovšek and V. Dananić, "Vibrational analysis of 3-glycidoxypropyltrimethoxysilane polymer," Macromol. Symp., 2014, vol, 339, pp 122-129.

[14] A. Venkateswara Rao, M. M. Kulkarni, D. P. Amalnerkar and T. Seth, "Superhydrophobic silica aerogels based on methyltrimethoxysilane precursor," J. Non-Cryst. Solids, vol. 330, pp 187-195, 2003.

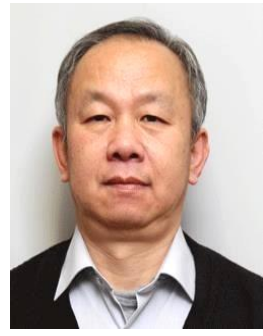

Y. X. Pang gained his $\mathrm{PhD}$ degree in polymer chemistry from Zhongshan University in 1988 . He is now a research senior lecturer in School of Science, Engineering and Design at Teesside University, UK. $\mathrm{He}$ is specialized in materials chemistry and has many years' research and development experience in advanced and functional materials through chemical, electrochemical and physical processing approaches. Current research interests include polymer and ceramic coatings with high temperature capability for electrical insulation and corrosion protection.

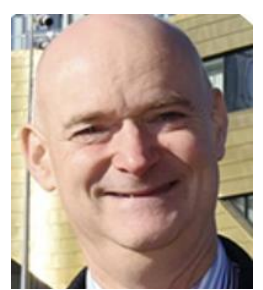

Simon N. B. Hodgson is Professor of Advanced Materials and Pro Vice-Chancellor for Research and Innovation at Teesside University. His specialist research field is in the area of inorganic and organicinorganic hybrid functional materials, coatings and nanocomposites by sol-gel, soft chemistry and related approaches together with their associated manufacturing processes.

\section{REFERENCES}

